\title{
Gestão da EaD no contexto dos polos de apoio presencial da Universidade Aberta do Brasil
}

\author{
Ipatinga - MG - 05/2015 \\ Márcia de Freitas Vieira - Universidade Aberta de Portugal - \\ marcia.ipatinga@gmail.com \\ Classe: Experiência Inovadora \\ Setor Educacional: Educação Superior \\ Classificação das áreas de pesquisa em EaD: Gerenciamento e \\ Organização
}

Natureza: Descrição de Projeto em andamento

\begin{abstract}
RESUMO
O trabalho visa apresentar os resultados parciais de uma pesquisa em andamento sobre o processo de gestão de cursos à distância no contexto dos polos de apoio presencial da Universidade Aberta do Brasil (UAB), com o objetivo de identificar as dificuldades e desafios desses polos nas suas práticas de gestão administrativa, financeira e pedagógica. Os métodos utilizados foram a pesquisa bibliográfica e o estudo de caso, com abordagem qualitativa e quantitativa. Foram realizadas análise documental, aplicação de questionários e entrevistas semiestruturadas a profissionais dos polos da UAB, situados nos municípios de Ipatinga, João Monlevade e Timóteo - Minas Gerais, no período de julho a agosto de 2013. Por meio do desenvolvimento do presente estudo foi possível observar que ainda existem muitos desafios para impulsionar progressivamente a qualidade da EaD, como: demanda de maiores investimentos em infraestrutura física e tecnológica, em especial, na internet banda larga e, ainda, nas questões cultural e profissional de alunos e professores que precisam conhecer melhor as especificidades desta eloquente modalidade de ensino.
\end{abstract}

Palavras chave: Gestão de EaD; Universidade Aberta do Brasil; Polo Presencial. 


\section{1 - Introdução}

A Educação a Distância é uma modalidade de ensino reconhecida pela Lei de Diretrizes e Bases da Educação (LDB) no 9.394/96 Art. 80. Subsidiada pelo uso das tecnologias de informação e comunicação, a educação a distância atinge um grande número de pessoas e revela-se como uma importante agente para a inclusão e a democratização da educação na sociedade do conhecimento. Socialmente desempenha um papel fundamental para 0 crescimento do nosso país.

Apesar dos inúmeros benefícios e facilidades de acesso, um dos maiores desafios que a EaD no Brasil enfrenta é o alto índice de evasão (Ferreira e Elia (2013), Moore e Kearley (2007)). Segundo Ferreira e Elia (2013, p.406), as causas da evasão em cursos de graduação oferecidos na modalidade de Educação à Distância no Brasil são:

\footnotetext{
fatores situacionais; falta de apoio acadêmico; problemas com a tecnologia; falta de apoio administrativo; sobrecarga de trabalho; organização do curso; problemas pessoais; relação com o professortutor; aprendizagem; tecnologia; relação interpessoal; limite pessoal; limite profissional; condições do polo e aspectos referentes ao curso e tutoria.
}

A implementação e manutenção de um curso superior é uma tarefa complexa, ainda mais quando se trata de um curso EaD. É mais que um simples projeto que alia tecnologia ao contexto da educação. Trata-se de um modelo de curso cuja característica e linguagem são diferenciadas.

O trabalho em questão apresenta os resultados parciais de uma pesquisa de doutorado em andamento, que analisa o processo de gestão de cursos à distância no contexto de alguns polos de apoio presencial da Universidade Aberta do Brasil.

\section{2 - Pressupostos teóricos}

Para a implantação e gestão de um curso a distância, é necessário que fatores internos, externos, estruturais, organizacionais e metodológicos sejam contemplados. A diversidade e a multiplicidade de concepções e tendências sobre a Educação a Distância é fundamental para a construção de propostas 
baseadas no diálogo e na compreensão de que existem diferentes perfis de instituições, alunos e organizações.

Alguns itens são considerados indicadores da qualidade do Ensino a distância, que norteariam a consecução e gerenciamento de um projeto de curso em EaD. Entre eles, Moreira, Safanelli, Cardoso e Battisti (2010, p. 4) destacam: integração com políticas, diretrizes e padrões de qualidade definidos para o ensino superior como um todo e para o curso específico; desenho do projeto; equipe profissional multidisciplinar; comunicação/interatividade entre professor e aluno; qualidade dos recursos educacionais; infraestrutura de apoio; avaliação de qualidade contínua e abrangente; convênios e parcerias; edital e informações sobre o curso de graduação a distância; custos de implementação e manutenção da graduação a distância.

A implementação e manutenção de um curso superior é uma tarefa complexa, ainda mais, quando se trata de um curso EaD. É mais que um simples projeto que alia tecnologia ao contexto da educação. Trata-se de um modelo de curso cuja característica e linguagem são diferenciadas. Assim, a criação e a manutenção de um curso nestes moldes exigem bem mais que uma simples discussão do melhor modelo pedagógico ou da estrutura curricular. Exige um adequado gerenciamento, a fim de garantir efetivamente o pleno desenvolvimento de atividades dos cursos.

Conforme Moreira, Safanelli, Cardoso e Battisti (2010, p.2), no contexto do Sistema UAB, "há uma sinergia entre União, Estados e Municípios em prol da consolidação de um ensino superior de qualidade e a distância". Entretanto, a EaD no Brasil ainda está em fase de adaptação. Apesar dos problemas decorrentes da escassez de normatização e instituições legais, que repercutem na implementação e gestão destes cursos, pouca atenção tem sido dispensada ao projeto de gerenciamento e manutenção dos mesmos.

Ainda, para os supracitados autores, para que as instituições que atuam ou pretendem atuar neste setor possam ter sucesso, não basta somente considerar a relação custo e benefício, o enfoque pedagógico e o conteúdo aplicado, deve-se buscar a implementação de um plano de gestão.

A criação e manutenção de um curso de EaD exige bem mais do que uma simples discussão do melhor modelo pedagógico ou estrutura curricular, ele exige um adequado gerenciamento a fim de se garantir efetivamente o pleno desenvolvimento das atividades dos cursos.[...] 
Neste sentido, criar mecanismos capazes de propiciar o planejamento, organização, capacitação da direção e de controle das atividades desenvolvidas. (MOREIRA et al, 2010, p. 3)

Um estudo realizado por Roque et al (2011), junto a professoresalunos de um curso de Licenciatura oferecido na modalidade a distância, sobre a qualidade destes cursos na perspectiva do cursista, mostrou que o fator visto como mais importante para a melhoria da qualidade do curso em questão é a melhor estruturação do momento presencial do mesmo (38\%). Os demais fatores citados estão relacionados a

\begin{abstract}
itens presentes no Projeto Político Pedagógico do curso, mais especificamente a Gestão Acadêmico-Administrativa, ou seja, o oferecimento de suporte administrativo; a garantia de uma logística de produção e distribuição de material didático; a avaliação de desempenho dos alunos e o registro dos resultados" (p.1560).
\end{abstract}

Essa pesquisa revela que, na ótica do aluno, o polo presencial é fator preponderante para o sucesso do curso. Isto deve-se, em parte, ao fato de que em muitas localidades no Brasil a conexão a internet é muito lenta, o que dificulta a participação do aluno pela web. A pesquisa aponta ainda "a importância de se conhecer bem o público-alvo na definição dos processos e metodologias a serem aplicadas nos cursos" (p.1562).

De acordo com Silva et al (2007, p.4),

a questão da gestão de um polo de apoio presencial está diretamente ligada a sua estrutura, formalmente definida e disciplinada pelo Sistema Universidade Aberta do Brasil. O êxito do Sistema, indubitavelmente, depende de seu bom funcionamento, que garanta uma estrutura administrativa e pedagógica adequada para atendimento e, fundamentalmente, gestores capacitados.

\title{
3 - Metodologia
}

Segundo Heerdt e Leonel (2007), o principal objetivo da pesquisa exploratória é proporcionar maior familiaridade com o objeto de estudo, por permitir a investigação que identifique as variáveis que se quer estudar. Dessa forma, o método escolhido foi o estudo de caso, que conforme Yin (2001) permite ao pesquisador mais de uma forma de coleta dos dados que o leve a obter resultados que possam traduzir-se de forma significativa o objeto estudado. A proposta é relatar de forma detalhada o objeto observado, como também permitir uma análise dos fatos e suas possíveis interações. 
Ao realizar o estudo de caso com característica exploratória, numa abordagem qualitativa e quantitativa, pretendeu-se conhecer o processo de gestão acadêmica, administrativa e financeira de cursos à distância no contexto dos polos de apoio presencial, através de visitação a alguns polos de apoio presencial da Universidade Aberta do Brasil. Assim, no período de julho a agosto de 2013, foram realizadas análise documental, aplicação de questionários e entrevistas semiestruturadas a profissionais de três polos presenciais da UAB em Minas Gerais, situados nos municípios de Ipatinga, João Monlevade e Timóteo.

No intuito de se obter uma maior abrangência do objeto investigado, foram analisadas opiniões de pessoas de posições hierárquicas diferentes, garantindo a representatividade de coordenadores pedagógicos, tutores de diferentes cursos e de titulação variada e de outros identificados no processo de pesquisa. Participaram ao todo, catorze profissionais, assim distribuídos: 05 do Polo UAB de Ipatinga, 06 do Polo UAB de João Monlevade e 03 do Polo UAB de Timóteo.

\section{4 - Cenário da pesquisa}

\section{1 - Perfil dos sujeitos}

No Polo da UAB, em Ipatinga, participaram da pesquisa, a coordenadora, um funcionário administrativo e três tutores presenciais, na faixa etária entre 38 e 54 anos, sendo quatro do sexo feminino e um do sexo masculino, com renda entre $R \$ 1.500,00$ e $R \$ 5.000,00$. Destes, um é mestre em Educação e os demais possuem pós-graduação (lato sensu) em nível de especialização em áreas diversas. O tempo de experiência em EaD dos entrevistados é, em média, de 3 a 5 anos.

No Polo da UAB, em João Monlevade, participaram da pesquisa, a coordenadora e quatro tutores presenciais, na faixa etária entre 36 e 56 anos, sendo três do sexo feminino e dois do sexo masculino, com renda entre $\mathrm{R} \$ 1.500,00$ e $\mathrm{R} \$ 4.500,00$. Destes, um é mestre em Pedagogia e os demais possuem pós-graduação em áreas diversas. O tempo de experiência em EaD dos entrevistados é, em média, de 3 a 5 anos. 
No Polo da UAB, em Timóteo, participaram da pesquisa, a coordenadora e dois tutores presenciais, na faixa etária entre 44 e 52 anos, sendo dois do sexo feminino e um do sexo masculino, com renda entre $R \$ 1.800,00$ e $R \$ 5.000,00$. Todos os entrevistados neste Polo possuem 2 ou mais cursos de pós-graduação lato sensu, e o tempo de experiência em EaD é acima de 5 anos.

Constata-se assim, que os sujeitos entrevistados deste Polo são bem qualificados e preparados para exercer a função que ocupam, o que é um ponto positivo para a gestão pedagógica e administrativa do Polo.

\section{2 - Os pólos UAB pesquisados}

O Polo da UAB de Ipatinga iniciou seu funcionamento em 2007. Em 2013, conta com cerca de 1000 alunos matriculados em 9 cursos de Graduação e 4 cursos de Especialização, ofertados pela Universidade Federal de Ouro Preto, Universidade de Brasília e Universidade Federal de Juiz de Fora.

O Polo da UAB de João Monlevade iniciou seu funcionamento em 2007. Em 2013, possui cerca de 840 alunos matriculados em 4 cursos de Graduação e 4 cursos de Especialização, ofertados pela Universidade Federal Fluminense e Universidade Federal de Ouro Preto, além de 2 cursos de aperfeiçoamento ofertadas pela Universidade Federal de Minas Gerais.

O Polo da UAB de Timóteo foi inaugurado em 2008. Em 2013, conta com cerca de 500 alunos matriculados em 4 cursos de Graduação e 6 cursos de Especialização, ofertados pela Universidade Federal de Ouro Preto, Universidade Federal de Juiz de Fora e Universidade Federal de São João Del Rei.

\section{5 - Apresentação e discussão dos resultados}

A pesquisa forneceu informações oportunas sobre os diferentes olhares que os profissionais envolvidos demonstram sobre a gestão dos cursos a distância nos Polos da UAB. As trajetórias desses Polos têm muitos pontos em comum e alguns distintos, que procuram atender a condições geográficas e 
de público-alvo específicas e a necessidades diferenciadas de gestão. Toda a infraestrutura física e de pessoal dos Polos de apoio presencial fica a cargo da prefeitura sede, enquanto que, para o MEC, fica a responsabilidade pelas despesas de infraestrutura física nas instituições e o custeio total dos cursos, envolvendo o pagamento de bolsas para docentes e tutores.

Na opinião dos respondentes dos três Polos, os fatores que influenciam positivamente na gestão administrativa, são: Profissionais qualificados e os relatórios de controle das atividades. Os respondentes do Polo de Ipatinga apontam como fatores que influenciam negativamente, as legislação/normas, infraestrutura física inadequada, estrutura tecnológica e a Internet banda larga. No Polo de João Monlevade, o único fator que influencia negativamente a gestão administrativa é o fato do Polo não ter sede própria e o local ser locado de terceiros, o que gera insegurança, pois, torna-se suscetível à perda desse espaço repentinamente. Já no Polo de Timóteo, a infraestrutura física inadequada e a Internet banda larga são os fatores que influenciam negativamente a gestão administrativa do mesmo.

Em relação à Gestão Financeira do Polo, os respondentes dos três Polos apontam a captação de recursos/convênios como influencia negativa. Isto devido à burocracia e morosidade no recebimento das verbas dos órgãos governamentais para as demandas apontadas pela coordenação do Polo. 50\% dos respondentes mencionaram que, como os cursos são ofertados através de convênio com Universidades Federais, não há ônus para os alunos e, conseqüentemente, não há inadimplência.

Com relação à gestão Pedagógica do Polo, a unanimidade dos respondentes apontaram como fatores que influenciam positivamente, o fato dos profissionais serem qualificados e atualizados com as necessidades da EaD e a qualidade do material didático. E como fatores negativos, o grande percentual de alunos despreparados para lidar com a EaD e o descrédito nessa modalidade de ensino.

Esses dados mostram que ainda existe muito preconceito em torno da EaD. Acredita-se que esse descrédito deve-se pelo desconhecimento de como funciona a metodologia e pelas primeiras iniciativas nesta modalidade que ofereceram cursos de baixa qualidade. E alunos despreparados para lidar com a Ead porque, em sua maioria, adultos, não conhecem as ferramentas que 
compõem as plataformas em que os cursos de EAD ocorrem e os recursos tecnológicos. Os alunos encontram dificuldades na utilização de fóruns, salas de discussão, blogs, wikis, e-mail, etc. Outro fator é a distância física do professor, o que muitas vezes, os fazem sentirem-se solitários e desmotivados.

Quando questionados sobre o que pensam a respeito da Gestão da educação à distância, a maioria dos respondentes enfatizou os desafios que a EaD ainda precisa vencer para se configurar como uma educação de qualidade, como podemos ver nos relatos a seguir: "ainda é um processo em fase embrionária e que pelo excesso de confiança de alguns dirigentes, está sendo prejudicado no seu desenvolvimento" (Ip1); "Muito centralizadora e tradicional, não reconhece os tutores como profissionais ferindo até mesmo a constituição" (Ip2); "A gestão da EaD depende em maior parte da atenção dada ao polo por seu mantenedor. As dificuldades administrativas são previsíveis e superáveis quando há suporte estrutural, de recurso humano e tecnológico oferecido pelo mantenedor" (Jm1). "O bom relacionamento com as universidades conveniadas é imprescindível” (Jm2). "O gestor tem que administrar muito bem os poucos recursos financeiros obtidos, além de organizar e deliberar sempre com os seus tutores, coordenadores e professores o melhor caminho para atingir os objetivos do curso" (Jm3). "É necessário investimentos variados para resgatar a credibilidade da modalidade" (Ti1). "Demanda habilidades e competências específicas para lidar com este sistema amplo, porém, carente de mecanismos que tornem esta clientela mais assídua e participativa de toda a engrenagem que a envolve" (Ti2).

O Polo presencial tem um papel importante como referência para o cursista da EaD. É a base física mais próxima do aluno, se não a única, onde o mesmo certamente terá apoio e subsídios para o pleno desenvolvimento de seu curso. A elevação do índice de aprendizagem do discente na educação a distância está atrelada ao desenvolvimento de algumas atividades pedagógicas no polo presencial, como por exemplo, o acompanhamento e a orientação para os estudos, as práticas laboratoriais, seminários, videoconferências e as avaliações presenciais. Portanto, os fatores estruturais e organizacionais de um polo de apoio presencial afetam diretamente a qualidade dos cursos ofertados e, conseqüentemente, o aprendizado dos alunos. 


\section{6 - Considerações finais}

Ainda são muitos os desafios enfrentados pelas IES para o funcionamento e a manutenção de um curso na modalidade $\mathrm{EaD}$, de forma a garantir a qualidade do processo ensino-aprendizagem e a redução nos índices de evasão: O primeiro desafio é o investimento em infraestrutura física e tecnológica, em especial, na internet banda larga e, o outro é cultural, ou seja, alunos e professores ainda precisam conhecer melhor essa modalidade de ensino, principalmente quanto à sua eficácia.

O exercício do ensino a distância por professores com certa carência formativa, especialmente para lidar com as novas tecnologias da informação e comunicação, causa a disseminação de práticas e conceitos equivocados. Tanto professores quanto alunos precisam de momentos de formação mais consistente e de melhor qualidade para que o acesso às novas tecnologias seja um facilitador do ensino e não gere frustração na hora de aprender e/ou ensinar.

Além desses, a busca constante das condições da produção e disseminação do conhecimento, o alto índice de evasão dos alunos, a dificuldade de avaliação, a exigência de conhecimentos na utilização de recursos tecnológicos precisam ser superados para que a Educação a Distância se configure como uma modalidade de ensino de melhor qualidade. A gestão de sistemas de EaD ainda precisa de fundamentação das práticas pedagógicas que permeiam a EaD e compreensão de suas especificidades no âmbito da gestão.

É fundamental a conscientização de todos os profissionais de que os polos presenciais e o campus da instituição de ensino tornam-se um ambiente único, sem distinções, separado apenas por limites geográficos. Deve-se criar a consciência de que os polos não são células desfragmentadas do corpo principal, mas, sim, uma unidade essencial para o seu desenvolvimento sustentável.

Nessa perspectiva, considera-se essencial a atuação dos polos presenciais, que são os elos entre a Instituição de Ensino Superior (IES) e a comunidade acadêmica. Corrobora-se que o polo UAB é um elemento muito 
importante para a qualidade do ensino a distância, porquanto ser nele baseado a gestão administrativa e financeira, o suporte para encontros presenciais e outras atividades necessárias à prática de estudo.

Conclui-se ainda que, para se avaliar um polo de apoio presencial da Universidade Aberta do Brasil é imprescindível se considerar a abrangência deste programa, que atinge as diferentes regiões do país, com as mais diversas características, discutindo, a partir disso, a complexidade de tal tarefa, já que é impossível desconsiderar esta diversidade. Dessa forma, conhecer cada região faz-se necessário, para traçar um panorama geral da gestão de cursos à distância no contexto dos polos de apoio presencial da Universidade Aberta do Brasil.

\section{Referências bibliográficas}

Brasil (2014). "Censo da Educação Superior 2012", INEP/MEC. Disponível em: http://portal.inep.gov.br/superior-censosuperior-sinopse. Acesso em 20/06/2014.

Ferreira, Vanessa da Silva; Elia, Marcos da Fonseca (2013). "Uma modelagem conceitual para apoiar a identificação das causas da evasão escolar em EAD" Anais do XIX WIE, Campinas, SP.

Heerdt, Mauri Luiz; Leonel, Vilson (2007). "Metodologia Científica e da Pesquisa". 5.ed.rev. - Palhoça: Unisul Virtual.

Moore, Michael; Kearsley, Greg (2007). "Educação a Distância: uma visão integrada". Tradução Roberto Galman. São Paulo: Thomson Learning.

Moreira, Bruno César de M.; Safanelli, Arcângelo dos S.; Cardoso, Jordana Maria Ramos; Battisti, Patrícia (2010). "Gestão acadêmica na educação a distância: desafios e práticas". X Coloquio Internacional sobre Gestión Universitária en América del Sur, p. 2-10.

Roque, Gianna Oliveira B.; Campos, Gilda Helena B.; Ziviani, Cílio; Fonseca, Marcus Vinícius A. (2011). "Qualidade em ead: o que pensam os cursistas?". Anais do XVII WIE, Aracaju - SE.

Silva, Edson Rosa Gomes da; Ribas, Júlio César da Costa; Moreira, Bruno César de Melo; Batistti, Patrícia; Pereira, Alice Theresinha Cybis (2007). "Gestão de polo de apoio presencial no sistema Universidade Aberta do Brasil: construindo referenciais de qualidade". Disponível em $<$ http://pigead.lanteuff.org/course/view.php?id=123>. Acesso em: 30 mar. 2013.

Yin, Robert K. (2001) "Estudo de caso: planejamento e métodos". 2. ed. Porto Alegre: Bookman. 